\title{
Couples' daily childcare schedules: gendered patterns and variations
}

\section{Abstract}

Gender inequality of childcare provision is regarded as one of the main barriers to women's labourmarket careers. However, there is a scarcity of quantitative studies that examine father's and mother's combined childcare. This research focuses on husband's and wife's timing and type of childcare for co-resident couples with a young child. Using the two most recent UK Time-Use Surveys, the study derives typologies of couples' childcare patterns with a particular focus on gender differences. The five patterns on weekdays and three patterns on weekend days highlight gender inequalities not just in the duration of parents' time with their children but also in its timing. Mothers are more often than fathers involved during standard working hours. The childcare patterns vary only modestly by occupational class. This might be related to the fluidity of couples' daily childcare patterns, which change with children's ages and across days of the working week.

Keywords: childcare, couples, gender, time use 


\section{Introduction}

Parental time with children and the type of activities that parents do with children are important for children's development and well-being (Gauthier, 2015). This is one of the reasons why modern mothers are expected to follow the ideal of 'intensive mothering' and invest large amounts of time and energy into raising their children (Hays, 1996). Also fatherhood ideals have changed and fathers are increasingly expected to be actively involved in bringing up their children (Marsiglio and Roy, 2012). These new ideals have led to an increase of fathers' and mothers' time with children (Fisher, McCulloch and Gershuny, 1999; Gauthier, Smeeding and Furstenberg, 2004; Sayer, Bianchi and Robinson, 2004). Hands-on childcare is becoming a joined commitment of both parents, turning parents' co-ordination of their childcare into a major concern.

Despite these changes, most fathers still adopt a breadwinner fathering style and prioritise employment, whereas mothers often adjust their work schedules to childcare needs (Connolly, Aldrich, O'Brien, Speight, and Poole, 2016; Miller, 2011). Because mothers also tend to provide longer hours of household work than fathers (Pailhé, Solaz and Tanturri, 2019), mothers end up providing considerably more hours of unpaid work than fathers. The unequal division of unpaid work is regarded as one of the main barriers to women's equality in the labour market (Bianchi, Sayer, Milkie and Robinson, 2012). In addition, combining paid work and childcare often leads to stress because of work-family conflict, especially in families with young children (Bellavia and Frone, 2005). Although the number of hours of childcare form a major aspect of the conflict, the timing of these hours may be even more important (Bianchi and Milkie, 2010).

The degree to which parents adjust their hours of paid work and the conflict they experience depends, among others, on the way that they organize their childcare. This study analyses the division of childcare in couples, taking its timing into account. So far very few quantitative studies have analyzed childcare from a couple perspective. Instead most quantitative studies juxtaposed childcare in a sample of fathers with childcare in a sample of mothers (Hook and Wolfe, 2013; Raley, Bianchi and Wang, 2012). The main exception is Craig and Mullan's (2011) cross-national study of 
fathers' and mothers' relative amounts of time in childcare. ${ }^{1}$ This paper takes a different approach by deriving a typology of fathers' and mothers' childcare involvement in the course of the day. It identifies major patterns based on the type and timing of each parent's involvement.

The aim of the paper is to identify and analyse the main childcare patterns of co-resident couples in the UK with children under the age of six. Couple childcare patterns (CCPs) refer to the combined daily schedules of childcare involvement by fathers and mothers. The analysis uses the UK Time-Use Surveys from 2000 (Ipsos-RSL, 2003) and 2014 (Gershuny and Sullivan, 2017). It derives CCPs from information about the gender, timing and intensity of parental involvement-whether the husband, the wife or both are involved and whether they are actively engaged or just accessible for the child. In the first part of the analysis, the diary entries about parents' childcare involvement are subjected to a sequence analysis and a cluster analysis to identify different patterns on weekdays and weekend days, respectively. The second part presents multinomial regression models to examine differences between CCPs by social class and couple employment patterns.

Qualitative research has discussed types of parents' combined work schedules that also speak to the co-ordination of their childcare (Becker and Moen, 1999; La Valle, Arthur, Millward, Scott and Clayden, 2002). La Valle and her co-authors (2002) analysed dual-working parents who worked atypical hours. Most couples practiced separate parenting roles, where one partner was the breadwinner and the other worked part time. These couples followed quite traditional roles and only used a minimal amount of non-parental childcare. Other couples practiced shift-parenting, where one partner, usually the man, worked standard hours and the other mainly worked when the partner was not at work or the children were at school. Finally, some couples had more equal parenting roles. In these couples both spouses tended to have professional jobs, having careers and relying on formal childcare (La Valle et al, 2002).

\footnotetext{
${ }^{1}$ Craig (2006) and Nock and Kingston (1988) analysed couples but did not compare husband's and wife's contributions within couples.
} 
Our analysis adds to this research by examining gendered childcare patterns in a representative sample of UK parents and systematically analysing social differences. After reviewing the literature, the paper describes the data, measures and statistical procedures before presenting two sets of findings - the CCPs on weekdays and weekend days and further analyses of these types using multivariate models. The discussion and conclusion explore the findings and their relevance.

\section{Background}

Couples' childcare arrangements are inextricably linked with decisions about parents' employment and the use of non-parental childcare. The study assumes that parents' childcare arrangements are shaped by their normative views about gender and parenting roles, and their resources and constraints to acting according to these views. Parents' income, their work schedules and flexibility, and their access to non-parental childcare are the main resources and constraints when it comes to childcare decisions. Couples with more traditional attitudes to gender and parenting roles will prefer a male breadwinner model if they can afford the loss of mother's income. Couples with less traditional attitudes to gender and parenting roles will try to share childcare more equally or use more non-parental childcare, including formal childcare if they can afford it.

Past research has shown continuing gender inequalities in the total hours of childcare (Bittman, Craig and Folbre, 2004; Craig and Mullan, 2011; Raley et al, 2012). Two prominent explanations for the gendered division of childcare are the time-constraints and the relative-resources approach. The time-constraints approach assumes that paid work and childcare are mutually exclusive and posits that the longer a parent's hours in paid work, the shorter their time in childcare. Whereas it is easy to agree that engaged childcare (Lamb, Pleck, Charnov, and Levine, 1985)-direct interactions between parents and children-cannot be combined with paid work, less intensive forms like being available to one's children is sometimes combined with other activities. However, the majority of parents cannot combine these less active forms of childcare with paid work. Therefore, both availability for and engagement with their children impose serious restrictions to parents' access to 
the labour market. The time-constraints approach has been confirmed for mothers but not for fathers (Coltrane, 1996; Hook and Wolfe, 2012).

The relative-resources approach conceives of childcare involvement as the outcome of negotiations that are based on individual resources of the spouses. The more resources a parent has relative to their partner, the less childcare they perform (Bianchi et al, 2012; Coltrane, 2000). Under this premise, mothers' higher involvement in childcare relative to fathers' can be explained by mothers' lower levels of resources relative to their husbands'. Recent research suggests that the relative resources approach is not appropriate for all aspects of childcare because parents enjoy some types of involvement; parents might only try to avoid the more onerous and inconvenient ones (Craig and Mullan, 2011; Raley et al, 2012). For these forms of childcare, the relative resources approach predicts a lower involvement by the more resourceful partner. Regarding the timing of childcare, the relative-resources approach predicts that the more resourceful partner will provide less childcare at times that are detrimental to their paid work career.

The third prominent explanation of the gendered division of childcare refers to gender-role attitudes and parenting ideals. Above I already referred to the changing expectations about fathers' and mothers' childcare involvement. Linked to these ideals are parents' attitudes to non-parental childcare. Many parents express a preference for parental care (La Valle et al, 2002; Lindsay and Maher, 2014). Although gender roles are becoming less traditional, only seven percent of British adults think that the mother of a pre-school child should work full time (Phillips, Curtice, Phillips and Perry, 2018). Less educated and low-income individuals hold more traditional views (Phillips et al, 2018: 66).

Despite these preferences it is common to use informal childcare by family or friends or formal childcare. Whereas the high costs and low availability of formal childcare have long been recognized as a barrier to mothers' work, recent policies have made part-time formal childcare more accessible for parents in the UK. By the year 2000, all four-year old children in the England were entitled to 412 
hours of free public childcare. ${ }^{2}$ This was extended to 570 hours for all three and four-year olds by 2015. Children start reception classes at school in the year when they turn five years old, staying in school from about 9 a.m. to 3 p.m.

Couples are more likely to use outside care when mothers work full time (Hook and Wolfe, 2012). Bittman, Craig and Folbre (2004) have shown that the distribution of childcare time between mothers and fathers becomes more equal as hours of non-parental care increase because of a reduction in mothers' time with children. The relationship between paternal and non-parental care or supervision is less straightforward. According to Bittman and his co-authors (2004), care outside the home was associated with an increase in fathers' involvement in low intensity care, that is, activities that require less effort and attention than, for example, feeding and bathing or teaching and telling stories.

One can distinguish two basic strategies of parents for achieving an equal division of childcare. On the one hand, both partners can be involved with their children at the same time. This usually constitutes family time, which facilitates the development of family solidarity. Most couples can provide this kind of childcare only for a limited amount of time. On the other hand, parents can practice shift parenting - taking turns to look after the children while the other parent is doing paid work. The main benefit of shift parenting is reducing reliance on third parties for childcare or supervision. Parents with flexible work schedules and control over these schedules should be better able to adapt their working hours to their childcare needs. Atypical schedules might pose a challenge to family time but they can also open up opportunities for shift-parenting because they can be used to de-synchronize parents' work time (Hook and Wolfe, 2013). High levels of non-day shifts or asynchronous work schedules of couples are associated with high rates of parental childcare, including father childcare (Lesnard, 2008; Lindsay and Maher, 2014; Presser, 2003).

Parental work schedules can also differ across different days of the week, providing the option of parents assuming the main childcare responsibility on different days. Atypical work schedules

\footnotetext{
${ }^{2}$ Childcare policy is a devolved issue and varies across the four nations of the UK.
} 
often comprise work on Saturdays or Sundays, allowing a trade-off of parental time between weekdays and weekend days (La Valle et al, 2002; Hook, 2012). Such schedules risk disrupting family time on weekend days because of the absence of a parent and the increased coordination efforts necessary for its constitution (Jurczyk, Schier, Szymenderski, Lange and Voß, 2009; Lesnard, 2008).

Atypical work schedules are just one factor that varies with couples' social position-the higher the position, the more standard workdays and the more synchronous are couples' workdays (Lesnard 2008; La Valle et al, 2002). According to the British Labour Force Survey (own calculations), fathers in professional and managerial occupations have become less likely to be scheduled to work on weekend days - their proportion decreased from $25 \%$ in 2001 to $17 \%$ in 2018 -whereas the prevalence has remained more or less stable around $29 \%$ for fathers in other occupational groups.

Several other factors that are relevant for the co-ordination of couple's childcare also differ between social classes. ${ }^{3}$ Middle-class parents tend to have more job flexibility (Dex and Ward, 2007) and more command over their working times (Craig and Powell, 2011; Lesnard, 2008). They can more easily afford high quality formal childcare and experience higher opportunity costs when reducing their hours of paid work. As mentioned above, middle-class couples also tend to adhere to less traditional gender roles. These differences make it easier for these parents compared to lowerclass parents to co-ordinate their work schedules around third-party childcare. However, middleclass parents support more strongly than working-class parents the ideology of intensive mothering (Hays, 1996). Lareau (2012) has described the particularly time-intensive parenting style of middleclass parents to foster their children's talents. This is in contrast to working-class parents who tend to give their children more unstructured time. Working-class fathers experience more barriers to their childcare involvement than middle-class fathers (Plantin, Månsson, and Kearney 2003). Timeuse studies of parental time with children have shown that middle-class parents devote more time to their children than parents from lower social classes (Gracia and Ghysels, 2017; Sullivan, 2010). Not only middle-class mothers but also middle-class fathers are more involved with their children

\footnotetext{
${ }^{3}$ The studies cited in this paragraph have operationalised social class in different ways, drawing on occupational position, level of education or income level.
} 
than their lower-class counterparts (Bianchi, Robinson and Milkie, 2006; Henz, 2019; Sayer et al, 2004).

Taken together, the paper addresses the following questions:

1) Which CCPs can be identified for UK parents of young children? How do they differ with respect to gendered hours of childcare and their timing?

2) How are parental strategies like shift parenting or the use of non-parental childcare associated with the different CCPs?

3) Do CCPs vary between social classes?

\section{Methods}

Data

The UK Time Use Surveys from 2000-01 (UKTUS 2000) and 2014-15 (UKTUS 2014) are very similar in their design. They report the activities of all adult household members for representative samples of UK households. This study uses information about all couples, whether married or not, who live together and have at least one child aged five years or younger. All adult household members were asked to fill in two diaries-one on a weekday and one on a weekend day-and report their activities for each 10-minute slot of the day. In UKTUS 2000, a total of 685 couples meet the selection criteria. For 216 of these couples, at least one partner had not completed the individual questionnaire or any diary, leaving 469 couples for the analysis. A few more cases have been excluded because of poor-quality diaries, the diaries of the couple not referring to the same calendar day, missing diaries of older children, or fathers being in full-time education. This reduces the final sample to 456 couples.

In UKTUS 2014, a total of 546 couples meet the original selection criteria but only 417 couples completed their individual interviews and at least one diary. As for UKTUS 2000, a few more cases were excluded, reducing the sample to 385 couples. The pooled sample of the two surveys comprises information from 820 couples on weekdays and 807 couples on weekend days. Both 
surveys used cluster sampling and provide weights for individuals and for diaries to adjust the distributions of key attributes to those of the UK population.

\section{Identifying couple childcare patterns}

The UK Time Use Surveys provide measures for parental engagement and accessibility. A parent is classified as being engaged during a 10-minute time slot if they report a childcare activity either as primary or secondary activity. ${ }^{4} \mathrm{~A}$ parent is classified as being available for a child if the parent is with a child but not actively engaged. The information about being with a child younger than eight years old is obtained from the corresponding indicator in the parent diary in both surveys. For children aged 10 and older the information is obtained in both surveys by comparing the locations reported in parents' and children's diaries. For children aged eight or nine years old, UKTUS 2000 only provides the indicator in parents' diary and UKTUS 2014 only the locations in parents' and children's diaries. Since all couples in this study have younger children that require the bulk of parental time, the disparity in the measures for this group of older siblings should be small relative to the total time of parental involvement.

The variable couple involvement is constructed by combining father's and mother's information about engagement with and availability to their children. Each 10-minute time slot of the day is coded to one of nine possible combinations. Figure 1 gives the categories and the average minutes that parents were engaged ('cares'), accessible ('with') or not involved with their children on weekdays and weekend days. For the rest of the paper the term involvement refers to any form of childcare, whether engagement or availability.

\footnotetext{
${ }^{4}$ In UKTUS 2014 participants could report more than two activities. For the seven cases where respondents mentioned childcare as a third activity, these childcare activities were recoded as secondary activity for this analysis.
} 
In order to derive a typology of couple childcare, it is necessary to quantify the difference in involvement in the course of a day between any two couples. These differences, or distances, are obtained by applying a sequence analysis (Martin and Wiggins, 2012) to the string of 144 indicators of couples' childcare involvement during the 24-hour day. The distance between two couples' involvement is calculated from the manipulations that are necessary to turn the childcare pattern of one couple into that of the other couple. The paper applies the Needleman-Wunsch algorithm (Martin and Wiggins, 2012) and specifies a cost of two for inserting or deleting one character. It sets a cost of two for substituting care by not involved for one parent; and a cost of one for substituting either care by with child or with child by not involved for one parent. All other substitution costs are derived from these costs, which are added for both parents. For example, reversing the gender pattern of engagement-replacing a spell of He cares, she not involved by She cares, he not involved attracts a cost of four, which is the highest possible substitution cost. All analyses are carried out separately for weekdays and weekend days, using the routines available in Stata (Brzinsky-Fay, Kohler and Luniak, 2006; Halpin, 2014).

The distances between couples are further analysed by cluster analyses with the Ward method (StataCorp, 2019). After examining the Calinski/Harabasz pseudo-F statistic for different possible numbers of clusters (StataCorp, 2019), I adopted a five-cluster solution on weekdays and a threecluster solution on weekend days. Table 1 gives the distributions of the childcare-related variables for weekday and weekend clusters.

The characteristics of couples in different childcare clusters will be compared by estimating multinomial logit models. The models regress the childcare clusters on father's and mother's occupational class and the couple's employment pattern, controlling for survey year and child composition. The measure for parental class is based on the National Statistics Socio-economic classification (NS-SEC)(ONS, 2016) and distinguishes three occupational classes: Managerial and 
professional occupations, Intermediate occupations and Routine and manual occupations. For women, a fourth category indicates individuals who have Never worked. Couple employment configurations distinguish couples where the father worked full time and the mother was not in paid work (Male-breadwinner couples), worked part time (1.5-breadwinner couples) or full-time (Dual full-time earner) and couples where the Father worked less than full time. The models include an indicator of whether the Mother has flexible work conditions. Indicators for father's flexible work conditions and for parental education were not statistically significant and excluded from the final analyses. The models control for survey year, child composition (age of youngest child, number of children (values ranging from 1 to 5)). Table 2 gives descriptive statistics for the explanatory and control variables by childcare cluster.

\footnotetext{
*** Tables 1 and 2 about here ***
}

\section{Findings}

Couple childcare clusters on weekdays

The cluster analysis identifies five different childcare patterns for weekdays. The times that couples spent in the different categories of couple involvement are given in Table 2. Figure 2 gives a rough representation of the five childcare patterns. The plots show the cumulative proportions of a simplified measure of couples' childcare involvement in the course of a weekday, distinguishing whether only the father was involved (i.e. engaged or accessible), only the mother was involved, or both parents were involved. Cluster 1 (Both/Father) is characterized by frequent simultaneous involvement of both spouses during the day and frequent sole involvement of the father throughout the day. Fathers in this cluster spend more time engaged and accessible on their own and the mothers spend the least amount of time as sole involved parent compared to the other clusters. Couples in this cluster report the longest average time for all types of simultaneous involvement. 
Cluster 2 (Mother) is formed by couples where the mother is the main carer with little involvement of the father. Mothers in this cluster spend nearly five hours engaged with a child and another 5.5 hours accessible for a child at times when the fathers are not involved. Also Cluster 3 (Mother/Both) consists of couples that rely predominantly on the mother for childcare during the day. In contrast to Cluster 2, fathers report more time with (mothers and) children in the evening. Overall, fathers in Cluster 3 are involved for nearly double the amount of time than fathers in Cluster 2 whereas the times reported by mothers are similar in both clusters. Couples in Cluster 3 report very little time without parental involvement.

Most couples in Cluster 4 (Nonparent 9-3) stop being involved with their children around 9 a.m. Some of them resume their involvement at midday but the majority does so at $3 \mathrm{p} . \mathrm{m}$. Immediately before and after the period without parental care, mothers but not fathers are involved with their children. Fathers' level of involvement is similar to Cluster 2 apart from an additional half hour when both parents are together with a child in the evening.

Couples in the fifth Cluster (LongNonparent) are only involved with their children for 380 minutes of the day, compared to 927 minutes in Cluster 3. Their involvement stops typically around 9 a.m. Before this time, both parents tend to be involved - alone or together - though mothers are more involved than fathers. Parents resume their childcare at varying times of the afternoon, many as late as 5 or 6 p.m. Both parents participate about equally in childcare in the evening, either in sole or synchronous involvement.

Mother and LongNonparent are the largest clusters in both years, each containing nearly $30 \%$ of the couples. Each of the other three clusters comprises about every seventh couple. Mother was more common in the 2014 than in the 2000 survey at the expense of several other clusters, mostly Mother/Both. 
The prevalence of shift-parenting is relatively high in the two Nonparent clusters, presumably because these clusters have the highest proportions of couples where both parents are in paid work. Despite this, shift-parenting for two hours or longer is quite rare. Such a pattern is most prevalent in the Mother cluster where some mothers start working for several hours in the early evening.

Couple childcare clusters on weekend days

For weekend days, the cluster analysis suggests a three-cluster solution. Table 2 gives the times that couples in the different clusters were engaged with or accessible for their children and Figure 3 gives simplified representations of the three patterns of couple childcare involvement.

Cluster 1 (Mother/Both) includes couples where only the mother is involved, in particular in the morning, before fathers join in during the afternoon. Fathers are predominantly involved simultaneously with the mother. Cluster $2($ Both) is formed by couples where for most of the day both partners are simultaneously involved with their children. In addition, fathers are involved for about two hours on their own and mothers for about three hours. Cluster 3 (Father/Nonparent) is characterized by a relatively low involvement of the mother and stronger involvement of the father. Parents in this cluster are only involved for about 9.5 hours in total compared to 15 or 16 hours in the other two clusters.

The cluster Both represents by far the most common childcare arrangement on weekend days. These parents have low levels of involvement in paid work on the weekend day compared to the other two clusters, where fathers (in Mother/Both) or fathers and mothers (in Father/Nonparent) do paid work for significant amounts of time. There is no difference in the distribution of the weekend clusters between the two survey years.

\footnotetext{
**** Figure 3 and Table 3 about here ${ }^{* * * *}$
} 
The left part of Table 3 gives the estimates from the multinomial logit models for weekday clusters. Because father's occupational class was not significant for predicting the weekday CCPs, the variable was dropped from the final model. Cluster membership on weekdays is strongly associated with the age of the youngest child. A further exploration of the data shows that the majority of couples with children younger than two years are in Mother and Mother/Both. As the youngest child grows older, couples are increasingly found in the Nonparent clusters. The prolonged periods without parental involvement reflect the entitlement of three and four-year olds to certain hours of formal childcare and the early age of schooling in the UK.

Panel A of Figure 4 illustrates the effects of selected variables from the model. The top part shows the predicted probabilities by couple employment patterns. In all childcare clusters there tends to be one form of couple employment that is overrepresented - Fathers working part time or not at all in the Father/Both cluster; Male-breadwinner couples in the Mother and the Mother/Both clusters; 1.5 -Breadwinner couples in the Nonparent9-3 cluster and Dual full-time working couples in the LongNonparent cluster. In addition, Dual-full-time working couples are underrepresented in the Father/Both, Mother and Mother/Both clusters whereas Male-breadwinner couples are underrepresented in the LongNonparent cluster. The lower part of panel A gives the predicted probabilities by mother's occupational class. Most childcare clusters represent mother's class fairly evenly with two exceptions: mothers in routine and manual occupations have an increased likelihood of being in the Mother cluster and a reduced likelihood of being in the LongNonparent cluster.

\footnotetext{
**** Figure 4 about here
}

The right-hand side of Table 3 gives the model estimates for weekend clusters. In contrast to weekdays, father's but not mother's occupational class was significant for predicting CCPs on weekend days. Therefore, mother's class was dropped from the final model. Panel B of Figure 4 
illustrates the estimated effects of couple employment pattern and father's occupational class. Male breadwinner couples stand out by being more likely to be in the Mother/Both cluster and less likely to be in the Father/Nonparent cluster compared to the other employment patterns. Couples with fathers in a professional or managerial occupation have a lower likelihood to be in the Mother/Both cluster and an increased likelihood of being in the Both cluster compared to the other two classes.

\section{Discussion}

This paper takes the analysis of gender inequality of parental childcare forward by jointly examining couples' childcare provision and by taking not just the duration but also the timing of parental childcare into account. The paper derives a typology of couple childcare patterns to ascertain the main aspects of parents' daily childcare schedules. It identifies five CCPs on weekdays in the UK. These are strongly correlated with children's ages, showing that couples adapt their childcare patterns to the changing needs of their growing children. However, within the constraints of children's needs, couples practiced a range of different childcare patterns regarding the extent to which parents rely on third parties for childcare or supervision, the extent to which both parents are synchronously involved with their children, and the duration and timing of each parent's involvement. On weekend days, three CCPs are identified, dominated by synchronous care and by sole involvement of the mother and the father, respectively.

The high significance of couple employment configuration corroborates the importance of time constraints for CCPs. Despite this strong relationship, the clusters exhibit a considerable internal diversity of couple employment configurations. For example, male-breadwinner couples were overrepresented in clusters where the mother cared during most of the day, but they constituted no more than $42 \%$ of couples in these clusters. Similarly, dual full-time earner couples were most common in the LongNonparent cluster, but $39 \%$ of couples in this cluster had different employment patterns. 
Taking a closer look at gender inequality, I find that in the clusters Mother, Mother/Both and Nonparent9-3 mothers had the main responsibility for childcare. Very few fathers were involved before $5 \mathrm{p} . \mathrm{m}$. and mothers remained involved for the rest of the afternoon and early evening even when fathers were present. Parents' contributions were most equal in the Father/Both cluster and the LongNonparent cluster. On the weekend, the Mother/Both cluster was gendered whereas the other two clusters were characterized by more equal levels of involvement of both parents.

The high level of gender equality in the Father/Both cluster results from the combination of two groups: 31 couples with fathers being the sole carer during significant parts of the day and 87 couples that were simultaneously involved during long periods of the day. Fathers' increased involvement in this cluster was possible because most of them performed hardly any paid work on the diary day. Indeed, a fifth of the fathers in Father/Both worked part time or were not in paid work at all. However, the remaining fathers reported on average the same number of weekly hours of paid work as fathers in the other clusters. Therefore, the diary day does not represent a standard working day of these fathers; they might have been sick, on annual leave or not being scheduled to work on this weekday. Unfortunately, the surveys do not allow further probing into these circumstances. Whatever the reason for fathers' low engagement in paid work on the diary day, the cluster shows that only very few fathers assumed the main responsibility for children on a weekday.

The two Nonparent clusters illustrate the role of non-parental care or supervision for couples' childcare patterns. In the Nonparent9-3 cluster, mothers were overwhelmingly responsible for handing over and collecting the children from other carers or supervisors and for looking after them during the remaining time within standard working hours. The cluster was most common at ages when children qualified for free public childcare or attended reception classes at school. In this cluster, non-parental care is coupled with gendered parenting roles. The LongNonparent cluster differs from the Nonparent9-3 by the longer times of non-parental care or supervision and a higher level of symmetry of parent involvement. During nearly a quarter of the total time that parents spent with their children only the father was involved, compared to $44 \%$ when only mother was 
involved. Mothers' hours of work increased the likelihood of being in the cluster, which supports the time availability hypothesis. Mothers' in managerial occupations were also overrepresented in the cluster, pointing to the importance of mothers' resources. In this cluster, non-parental childcare or supervision ended later in the afternoon and was associated with rather equal childcare patterns.

Similar to non-parental care, shift-parenting featured in both traditional and non-traditional CCPs. Shift-parenting can be a parental strategy to simultaneously extend parental time with children and paid-work time. Such a pattern was most common in the Nonparent clusters where in $11 \%$ of couples each partner looked after a child for at least one hour while the other parent was at work. Far fewer couples practiced shift-parenting for longer durations. Therefore, shift-parenting seems to be predominantly a strategy for fine-tuning schedules in the Nonparent clusters. In contrast, $6 \%$ of couples in the Mother cluster practiced shift-parenting for at least two hours per parent. Some of these mothers started several hours of paid work in the evening. These couples correspond to the couples described by Presser (2003) and LaValle and her co-authors (2002) who use shift-parenting to avoid non-parental care. According to this analysis, very few parents of young children in the UK practice this strategy.

According to the analyses, CCPs are moderately associated with social class. On weekdays, mother's but not father's occupational class mattered for the couple's CCP. This finding confirms the lasting power of traditional gender roles according to which women have the main responsibility for childcare. Women in routine occupations are overrepresented in the most traditional cluster and underrepresented in the Long-Nonparent cluster. It is possible that this is because of their parenting values but these women could also face barriers to other forms of childcare. Fathers in managerial and professional occupations are underrepresented in the most traditional weekend cluster. In this cluster, fathers worked on average for five hours on the weekend day whereas only very few fathers in the Both cluster worked on the weekend day. Since higher-class fathers tend to have more standardized working times (Lesnard, 2008) and are less likely to be scheduled to work on weekend days (own calculations reported above), their underrepresentation in the Mother/Both cluster might 
point to a class privilege of these fathers that protects their family time on weekends. However, more research is needed to test this conjecture against, for example, possible class differences in valuing family time on the weekend.

\section{Conclusions}

The majority of CCPs on weekdays display traditional gender roles. Mothers are not just involved for longer hours than fathers but they are also more often involved during standard working hours and they are more often responsible for managing transitions between parental care and other types of care or supervision. Only few fathers are responsible for childcare during the day on a weekday. These differences confirm earlier findings about the gender inequality of couples' childcare. However, they go beyond these to show how childcare narrows mothers' availability for paid work to few hours during the day or to unusual hours. Thereby, these mothers are excluded from many attractive labour-market positions, which reinforces gender inequality in couples.

The main gender-equal childcare pattern on weekdays relies on long hours of non-parental care. The unique feature of the cluster is not just the long duration of non-parental care but its combination with father's sole involvement during the afternoon and evening. Mother's high occupational position might boost both of these. The study found very few cases of role reversal, that is, of fathers being solely responsible during the main part of the working day. Shift parenting played a certain role for fine-tuning schedules but very few British parents of young children used it to minimize the need for alternative sources of childcare.

The models identify only few strong predictors of CCPs apart from children's age. The proportion of at least $22 \%$ of full-time working women in each cluster, including the Mother and Mother/Both clusters, suggests that many couples do not follow the same CCP every day. This might also be the reason for finding no differences by parental education and only weak differences by occupational class. Combining work and childcare in the flexible UK labour market means that parents constantly juggle their work and care (LaValle et al, 2002). It underlines the necessity to 
analyze weekly work and care schedules instead of daily schedules (Hepburn, 2018). On the one hand, the finding highlights the need for policies that support highly flexible childcare arrangements, both regarding institutional provision and increased involvement of fathers earlier in the day. On the other hand, the findings raise questions about complex schedules and a lack of family time in gender-equal couples.

The study has several limitations. Parents who co-parent across households cannot be included because the surveys do not provide the necessary information for these couples. For the same reason, the study includes only two dimensions of childcare and neglects the third dimension, parental responsibility for their children (Lamb et al, 1985). Similarly, information about gender-role attitudes is not available. With a larger sample, the study might have identified more nuanced CCPs. However, the UK HETUS surveys are among few time-use surveys that interviewed both partners, enabling the identification of childcare patterns that are representative for UK co-resident parents. The findings underline the need to collect information about weekly work and childcare schedules to fully ascertain CCPs. Last but not least, it is not possible to establish causal relationships from analyzing a cross-sectional survey like the UK HETUS. However, by mapping couples' childcare schedules the analysis highlights the gender differences not just in the amounts but also in the timing of childcare.

\section{Funding details}

No external funding was received for this study.

\section{Conflict of interest statement}

The author declares that there is no conflict of interest.

\section{Acknowledgement}


All datasets were accessed through the UK Data Service. The United Kingdom Time Use Survey 2000 (SN: 4504, http://doi.org/10.5255/UKDA-SN-4504-1) was deposited by Ipsos-RSL and the UK Office for National Statistics. Jonathan Gershuny and Oriel Sullivan deposited the United Kingdom Time Use Survey 2014-2015 (SN: 8128, http://doi.org/10.5255/UKDA-SN-8128-1). Auxiliary analyses use the British Labour Force Survey Households Datasets (http://doi.org/10.5255/UKDA-SN-5461-1 and http://doi.org/10.5255/UKDA-SN-8389-2), which were deposited by the Office for National Statistics.

\section{References}

Becker, P.E., and Moen, P. (1999) 'Scaling back: Dual-earner couples' work-family strategies', Journal of Marriage and The Family 61(4): 995-1007.

Bellavia, G., and Frone, M. (2005) 'Work-Family Conflict', in J. Barling, E. K. Kelloway and M. Frone (eds) Handbook of Work Stress, Sage Publications, Thousand Oaks. pp. 113-48.

Bianchi, S.M., Robinson, J.P., and Milkie, M.A. (2006) Changing rhythms of American family life. New York: Russell Sage.

Bianchi, S.M., and Milkie, M.A. (2010) 'Work and family research in the first decade of the 21st century', Journal of Marriage and Family 72(3): 705-25.

Bianchi, S.M., Sayer, L.C., Milkie, M.A., and Robinson, J.P. (2012) 'Housework: Who did, does or will do it, and how much does it matter?', Social Forces 91(1): 55-63.

Bittman, M., Craig, L., and Folbre, N. (2004) 'Packaging care: What happens when children receive nonparental care?', in N. Folbre and M. Bittman (eds) Family time. The social organization of care, London and New York, Routledge. pp: 133-51.

Brzinsky-Fay, C., Kohler, U., and Luniak, M. (2006) 'Sequence analysis with Stata', The Stata Journal 6: 435-60.

Coltrane, S. (1996) Family man. New York and Oxford: Oxford University Press.

Coltrane, S. (2000) 'Research on household labor: Modeling and measuring the social embeddedness of routine family work', Journal of Marriage and Family 62(4): 1208-33. 
Connolly, S., Aldrich, M., O’Brien, M., Speight, S., and Poole, E. (2016) ‘Britain's slow movement to a gender egalitarian equilibrium: parents and employment in the UK 2001-12', Work, Employment and Society 30(5): 838-57.

Craig, L. (2006) ‘Does father care mean fathers share?', Gender and Society 20(2): 259-281.

Craig, L., and Mullan, K. (2011) 'How mothers and father share childcare: A cross-national time use comparison', American Sociological Review 76: 834-61.

Craig, L., and Powell, A. (2011) ‘Non-standard work schedules, work-family balance and the gendered division of childcare', Work, employment and society 25(2): 274-291.

Dex, S., and Ward, K. (2007) Parental care and employment in early childhood, Equal Opportunities Working Paper No. 57. London: Equal Opportunities Commission.

Fisher, K., McCulloch, A., and Gershuny, J. (1999) 'British fathers and children: A report for Channel 4 'Dispatches', Colchester: University of Essex: Institute for Social and Economic Research.

Gauthier, A.H. (2015) 'Social class and parental investment in children', in Scott, R. and S. Kosslyn (eds): Emerging Trends in the Social and Behavioral Sciences, John Wiley online publication, DOI: $10.1002 / 9781118900772$.

Gauthier, A.H., Smeeding, T.M., and Furstenberg, F.F., Jr (2004) 'Are parents investing less time in children? Trends in selected industrialized countries', Population and Development Review 30(4): 647-71.

Gershuny, J., and Sullivan, O. (2017) United Kingdom Time Use Survey, 2014-2015. Centre for Time Use Research, University of Oxford. [data collection]. UK Data Service. SN: 8128. Available at: http://doi.org/10.5255/UKDA-SN-8128-1.

Gracia, P., and Ghysels, J. (2017) 'Educational inequalities in parental care time: Cross-national evidence from Belgium, Denmark, Spain and the United Kingdom', Social Science Research 63: 166-80.

Halpin, B. (2014) SADI: Sequence Analysis Tools for Stata, WP2014-03, Department of Sociology, University of Limerick, Ireland. Available at: www.ul.ie/sociology/pubs/wp2014-03.pdf. 
Hays, S. (1996) The Cultural Contradictions of Motherhood, New Haven: Yale University Press.

Henz, U. (2019) 'Fathers' involvement with their children in the United Kingdom: Recent trends and class differences', Demographic Research 40: 865-96.

Hepburn, P. (2018) 'Parental work schedules and child-care arrangements in low-income families', Journal of Marriage and Family 80(5): 1187-209.

Hook, J.L. (2012) 'Working on the weekend: Fathers' time with family in the United Kingdom', Journal of Marriage and Family 74(4): 631-642.

Hook, J.L., and Wolfe, C.M. (2012) 'New fathers? Residential fathers' time with children in four countries', Journal of Family Issues 33(4): 415-50.

Hook, J.L., and Wolfe, C.M. (2013) 'Parental involvement and work schedules: Time with children in the United States, Germany, Norway and the United Kingdom', European Sociological Review 29(3): 411-25.

Ipsos-RSL, Office for National Statistics (2003) United Kingdom Time Use Survey, 2000. [data collection]. 3rd Edition. UK Data Service. SN: 4504, http://doi.org/10.5255/UKDA-SN-4504-1

Jurczyk, K., Schier, M., Szymenderski, P., Lange, A., and Voß, G.G. (2009) Entgrenzung von Arbeit Entgrenzung von Familie. Grenzmanagement im Alltag als neue Herausforderung [Blurring the boundaries of work - blurring the boundaries of family. Boundary management in everyday life as a new challenge], Berlin: edition sigma.

Lamb, M.E., Pleck, J.H., Charnov, E.L. and Levine, J.A. (1985) ‘Paternal behaviour in humans', American Zoologist 25: 883-94.

Lareau, A. (2012) Unequal Childhoods: Class, Race, and Family Life, Berkeley: University of California Press.

La Valle, I., Arthur, S., Millward, C., Scott, J., and Clayden, M. (2002) Happy families? Atypical work and its influence on family life, Bristol: Policy Press and Joseph Rowntree Foundation.

Lesnard, L. (2008) 'Off-scheduling within dual-earner couples: An unequal and negative externality for family time', American Journal of Sociology 114(2): 447-90. 
Lindsay, J., and Maher, J.M. (2014) 'The intersection of work time and care time: nurses' and builders' family time economies', Work, employment and society 28(2): 189-205.

Marsiglio, W., and Roy, K. (2012) Nurturing dads: Social initiatives for contemporary fatherhood, New York: Russell Sage.

Martin, P., and Wiggins, R.D. (2012) 'Optimal matching analysis', in M. Williams and W.P. Vogt (eds) The SAGE handbook of innovation in social research methods, London, Sage. pp: 385-408.

Miller, T. (2011) ‘Falling back into gender? Men's narratives and practices around first-time fatherhood, Sociology 45(6): 1094-109.

Nock, S.L., and Kingston, P.W. (1988) 'Time with children: The impact of couples' work-time commitments', Social Forces 67(1): 59-85.

ONS (2016): The National Statistics Socio-economic classification (NS-SEC). Office for National Statistics, UK.

https://www.ons.gov.uk/methodology/classificationsandstandards/otherclassifications/thenati onalstatisticssocioeconomicclassificationnssecrebasedonsoc2010

Pailhé, A., Solaz, A., and Tanturri, M. L. (2019) 'The time cost of raising children in different fertility contexts: Evidence from France and Italy', European Journal of Population 35(2): 223-61.

Phillips, D., Curtice, J., Phillips, M., and Perry, J. (Eds.) (2018) British social attitudes: the $35^{\text {th }}$ report, London: The National Centre for Social Research.

Plantin L., Månsson S.-A., and Kearney, J. (2003) 'Talking and doing fatherhood: On fatherhood and masculinity in Sweden and England', Fathering 1(1): 3-26.

Presser, H.B. (2003) Working in a 24/7 economy, New York: Russell Sage.

Raley, S., Bianchi, S.M., and Wang, W. (2012) 'When do fathers care? Mothers' economic contribution and fathers' involvement in child care', American Journal of Sociology 117(5): 1422-59.

Sayer, L.C., Bianchi, S.M., and Robinson, J.P. (2004) 'Are parents investing less in children? Trends in mothers and fathers time with children', American Journal of Sociology 110(1): 1-43. 
StataCorp (2019) Stata: Release 16. Statistical Software, College Station, TX: StataCorp LLC.

Sullivan, O. (2010) 'Changing differences by educational attainment in fathers' domestic labour and child care', Sociology 44(4): 716-33. 